\title{
BMJ Open HIV counselling and testing practices for children seen in an urban emergency department of a tertiary referral hospital in Dar es Salaam, Tanzania: a retrospective cross-sectional study
}

\author{
Hendry R Sawe, ${ }^{1,2}$ Juma A Mfinanga, ${ }^{1,2}$ Faith H Ringo, ${ }^{2}$ Victor Mwafongo, ${ }^{1,2}$ \\ Teri A Reynolds, ${ }^{1,3}$ Michael S Runyon ${ }^{1,4}$
}

To cite: Sawe HR, Mfinanga JA, Ringo FH, et al. HIV counselling and testing practices for children seen in an urban emergency department of a tertiary referral hospital in Dar es Salaam, Tanzania: a retrospective crosssectional study. BMJ Open 2016;6:e010298.

doi:10.1136/bmjopen-2015010298

- Prepublication history for this paper is available online. To view these files please visit the journal online (http://dx.doi.org/10.1136/ bmjopen-2015-010298).

Received 20 October 2015 Revised 21 December 2015 Accepted 15 January 2016

CrossMark

For numbered affiliations see end of article.

Correspondence to Dr Michael S Runyon; michael.runyon@carolinas. org

\section{ABSTRACT}

Objectives: To describe the HIV counselling and testing practices for children presenting to an emergency department (ED) in a low-income country. Setting: The ED of a large east African national referral hospital.

Participants: This retrospective review of all paediatric (<18 years old) ED visits in 2012 enrolled patients who had an HIV test ordered and excluded those without testing. Files were available for 5540/5774 (96\%) eligible patients and 1632 (30\%) were tested for HIV, median age 1.3 years (IQR 9 months to 4 years), $58 \%<18$ months old and $61 \%$ male.

Primary and secondary outcome measures: The primary outcome measure was documentation of pretest and post-test counselling, or deferral of counselling, for children tested for HIV in the ED. Secondary measures included the overall rate of HIV testing, rate of counselling documented in the inpatient record when deferred in the $E D$, rate of counselling documented when testing was initiated by the inpatient service, rate of counselling documented by test result (positive vs negative) and the rate of referral to follow-up HIV care among patients testing positive.

Results: Of 418 patients tested in the ED, counselling, or deferral of counselling, was documented for 70 $(17 \%)$. When deferred to the ward, subsequent counselling was documented for $15 / 42(36 \%)$. Counselling was documented in $33 \%$ of patients testing positive versus $1.1 \%$ patients testing negative (OR 43 (95\% Cl 23 to 83). Of 199 patients who tested positive and survived to hospital discharge, 76 (38\%) were referred for follow-up at the HIV clinic on discharge.

Conclusions: Physicians documented the provision, or deferral, of counselling for $<20 \%$ of children tested for HIV in the ED. Counselling was much more likely to be documented when the test result was positive. Less than $40 \%$ of those testing positive were referred for follow-up care.

\section{Strengths and limitations of this study}

- Tanzania HIV guidelines recommend providerinitiated HIV testing and counselling for all patients presenting to healthcare facilities regardless of whether they have signs or symptoms of HIV infection, however, no study has documented the implementation of and compliance with this recommendation in an acute intake or emergency department setting.

- This study is the only study carried out nationwide looking at provider HIV counselling experiences in emergency department settings in Tanzania, and was performed at the acute intake area of the largest national hospital.

- Few studies worldwide have been conducted to assess provider HIV counselling experiences with regard to paediatric patients in areas of high HIV prevalence within low resource settings.

- The study was limited by the fact that it was a retrospective chart review; therefore it may underestimate the true number of counselling episodes if they were not well documented.

- HIV diagnosis and counselling are essential to the proper management of paediatric patients with HIV; research into the real-world implementation of testing and counselling guidelines is essential.

\section{INTRODUCTION}

In developing countries, HIV/AIDS remains a major public health concern causing catastrophic health and socioeconomic effects, with children representing an especially vulnerable population. ${ }^{1}$ Globally, there were approximately 35 million people living with HIV in 2013, including 3.3 million children, and over 200000 AIDS-related deaths. ${ }^{1}{ }^{2}$ Sub-Saharan Africa carries the greatest burden of disease, sheltering over two-thirds 
of the total number of people living with HIV/AIDS, while accounting only for about $12 \%$ of the world's population. More than three quarters of HIV/AIDSrelated deaths among children occur in sub-Saharan Africa. ${ }^{2}$ Mother-to-child transmission remains the most common route of transmission in children under the age of 15 years. ${ }^{3}$

Mortality among HIV-positive children not treated with highly active antiretroviral therapy (HAART) is estimated at $35 \%$ by the age of 1 year and over $50 \%$ by the age of 2 years. ${ }^{4-6}$ The introduction of HAART has significantly decreased mortality and, with treatment, most HIV-infected infants and children are now able to survive into adolescence and adulthood. Many studies have shown that early diagnosis, timely treatment with HAART and close follow-up of children with HIV infection has led to decreases in HIV mortality, progression to AIDS and hospital admission rates. ${ }^{7-9}$

Owing to the burden of disease, the Tanzania HIV guidelines recommend that healthcare providers initiate counselling and testing for all patients presenting to a health facility regardless of whether or not the patients have signs or symptoms of HIV infection. In the case of children, pretest and post-test counselling must be given to the responsible parent, guardian or close relative. The guidelines state that HIV testing and counselling services provided must be documented in medical records to ensure continuity of care. ${ }^{10}$

The Muhimbili National Hospital (MNH) opened the first and, at the time, only full capacity emergency department (ED) in Tanzania in January 2010; the department receives in the range of 36000 ill and injured patients annually, including approximately 7000 children. ${ }^{11}{ }^{12}$ In an attempt to provide appropriate and timely treatment and stabilisation of ED patients, bedside testing, including rapid HIV testing, may be performed based on the nature of the patient presentation. Hospital policy is that the attending physician will provide, and document, pretest and post-test counselling services to the parent or guardian of all paediatric patients who are tested in the ED. When the severity of the patients' illness precludes counselling in the ED, documentation of the HIV testing and results are to be clearly noted in the chart, and communicated to the admitting physician, along with the fact that counselling was deferred, to alert the inpatient health workers to the need for appropriate post-test counselling and referral for follow-up care. In cases when counselling is deferred in the ED or when the HIV test is performed in the ward, the pretest and post-test counselling is to be documented in the medical record by the inpatient team, and the patient referred to a HIV care and treatment centre (CTC) at discharge, to ensure continuity of care.

This study aimed at assessing the adequacy of paediatric HIV testing and counselling practices for all paediatric patients seen at the MNH ED in the year 2012. We hypothesised that physicians would document pretest and post-test counselling, or deferral of counselling, in fewer than one half of patients tested for HIV at the $\mathrm{MNH} \mathrm{ED}$, and that documentation rates would be higher among patients testing positive as compared with those testing negative.

\section{METHODS}

\section{Study design}

This was a retrospective review of all paediatric visits to the MNH ED from 1 January 2012 to 31 December 2012.

\section{Study setting and population}

The MNH ED, the first of its kind in Tanzania, was established in 2010, via a public-private partnership between the Ministry of Health and Social Welfare, and Abbott Fund Tanzania. MNH is the largest tertiary care centre in Tanzania and the ED is the clinical training site for the only emergency medicine residency programme in the country. Physician staffing includes interns (fresh medical school graduates), registrars (registered medical practitioners who are 1-3 years postinternship) and emergency medicine residents (all of whom worked as registrars before joining the 3-year residency programme). Locally trained emergency physicians provide clinical supervision, with support from board-certified emergency physicians from the USA, Canada and South Africa. The department serves a high-acuity patient population from within Dar es Salaam and receives referral patients from throughout the country. Of the approximately 36000 patients seen each year, only $20 \%$ are discharged home from the ED. The top five categories of symptoms seen in the department are trauma, infection, mental health, neoplasm and pregnancyrelated issues. ${ }^{11}$

\section{Study protocol}

The study was designed and conducted according to the accepted standards for emergency medicine chart reviews, ${ }^{13}$ except that the abstractors were not blinded to the study hypothesis. We identified all paediatric patients ( $<18$ years old) who presented to the MNH ED from 1 January to 31 December 2012, by query of our hospital's registration system (Jeeva-Online Health Information System, Karishma Software Ltd, Singapore). Trained physician abstractors reviewed each patient's chart. Study data were recorded on a structured data sheet and included patient demographics, whether HIV testing was performed and, if so, the result of the test, and whether pretest and post-test counselling was documented. It is standard practice for pretest and post-test counselling to be documented in a single note in the ED chart, and in separate entries in the inpatient record. As such, counselling was recorded as a single dichotomous variable for patients tested in the ED and as two separate variables when testing was initiated in the ward. For those testing HIV positive, the abstractors noted whether the patients 
were referred to a CTC clinic for follow-up care and initiation of HAART.

\section{Key outcome measures}

The primary outcome measure was emergency physician documentation of pretest and post-test counselling, or documentation of deferral of counselling, for paediatric patients tested for HIV during their ED stay. Secondary measures included: (1) overall rate of HIV testing among children seen in the MNH ED in 2012; (2) proportion of cases in which pretest and post-test counselling was documented in the inpatient record after being deferred in the ED; (3) proportion of cases in which pretest and post-test counselling was documented in the inpatient record when testing was initiated by the inpatient service; (4) proportion of cases in which pretest and post-test counselling was documented for patients testing HIV positive versus those testing HIV negative and (5) rate of referral to CTC clinic among patients testing positive who survived to hospital discharge.

\section{Data analysis}

Data were imported into an Excel spreadsheet (Microsoft Corporation, Redmond, Washington, USA), cleaned, and analysed using Stats Direct (V.2.8.0, Cheshire, UK). Continuous data are summarised as medians and IQRs, and categorical data are summarised as counts and percentages, with 95\% CIs presented for the outcome variables. The impact of the test result (positive or negative) on the rate of documentation of counselling (counselling documented or not) was compared with the $\chi^{2}$ test and the corresponding OR and 95\% CI. A second physician investigator independently reviewed a randomly selected subset of $126(10.4 \%)$ charts to determine whether or not counselling was documented, and we assessed the degree of interobserver agreement beyond that expected by chance, using the unweighted Cohen's $\kappa$ and corresponding $95 \%$ CI. $^{14}$

\section{RESULTS}

A total of 5774 paediatric patients were seen at $\mathrm{MNH}$ from 1 January to 31 December 2012. Of these, 5540 $(95.9 \%)$ charts were available for data abstraction and $1632 / 5540(29.5 \%)$ had a HIV test order documented, including 418 in the ED and an additional 1214 tested during their inpatient stay (figure 1). Among the 1632 patients tested for HIV, the median age was 1.3 years (IQR 9 months to 4 years), $938 \quad(57.5 \%)$ were $<18$ months old and $994(60.9 \%)$ were male (table 1$)$.

\section{Primary outcome}

Of 418 patients tested for HIV in the ED, emergency physicians documented the provision of pretest and post-test counselling, or deferral of counselling to the inpatient service, in $70(16.7 \%$, 95\% CI $13.3 \%$ to $20.7 \%)$ cases (table 2).

\section{Secondary outcomes}

The overall rate of HIV testing among children seen in the $\mathrm{MNH} \mathrm{ED}$ in 2012 was $418 / 5540$ (7.5\%, 95\%

Figure 1 Study flow diagram.

ED, emergency department;

$\mathrm{MNH}$, Muhimbili National

Hospital.

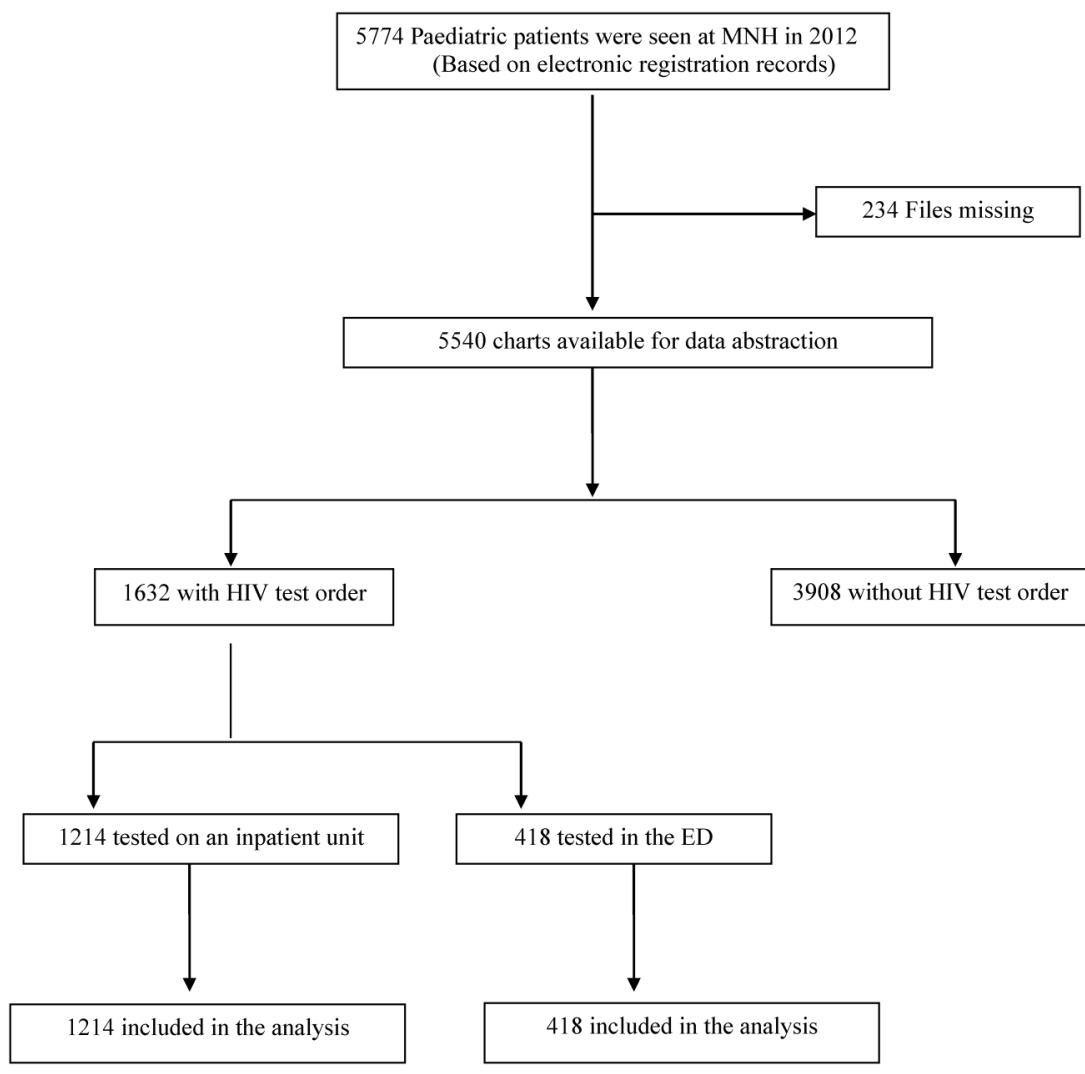


Table 1 Demographic data of the study population*

$\begin{array}{ll}\text { Age } & \mathrm{n}=1632 \\ \text { Overall, median (IQR) } & 1.3 \text { years (9 months to 4 years) } \\ \text { Birth to } 6 \text { months } & 243(14.9) \\ 6 \text { to } 18 \text { months } & 695(42.6) \\ 18 \text { months to } 5 \text { years } & 348(21.3) \\ \text { Over } 5 \text { years } & 346(21.2) \\ \text { Gender } & \\ \text { Male } & 994(60.9) \\ \text { Female } & 638(39.1) \\ \text { "Except as noted, values are counts }(\%) .\end{array}$

CI $6.9 \%$ to $8.3 \%$ ) (figure 1 ). Of the 42 patients undergoing HIV testing in the ED for whom counselling was documented as deferred to the inpatient setting, subsequent counselling was documented in the inpatient record in $15(35.7 \%, 95 \%$ CI $21.6 \%$ to $52.0 \%)$ cases (table 2). Of the 1214 patients who had HIV testing initiated by the inpatient service, pretest and post-test counselling was documented in $176(14.5 \%, 95 \%$ CI $12.6 \%$ to $16.6 \%$ ) cases (table 2 ).

HIV test results were available in the medical record for 1213 of 1632 patients $(74.3 \%, 95 \%$ CI $72.1 \%$ to $76.4 \%)$. When counselling patterns were analysed by test result, pretest and post-test counselling was documented in $79 / 239(33.1 \%, 95 \%$ CI $27.1 \%$ to $39.4 \%)$ patients testing positive versus $11 / 974(1.1 \%, 95 \%$ CI $0.6 \%$ to $2.0 \%$ ) patients testing negative (OR 43, 95\% CI 23 to 83 , $\mathrm{p}<0.0001$ ) (table 3).

Among the 239 patients testing positive for HIV, 199 $(83.3 \%, 95 \%$ CI $77.9 \%$ to $87.8 \%)$ survived to hospital discharge and $76 / 199(38.2 \%, 95 \%$ CI $31.4 \%$ to $45.3 \%)$ were referred for follow-up at a CTC on discharge (table 4).

\begin{tabular}{|c|c|}
\hline $\begin{array}{l}\text { HIV testing performed in the } \\
\text { ED }\end{array}$ & $\mathrm{n}=418$ \\
\hline Counselling documented & $28(6.7 ; 4.5$ to 9.5$)$ \\
\hline $\begin{array}{l}\text { Counselling documented as } \\
\text { deferred }\end{array}$ & $42(10 ; 7.3$ to 13.3$)$ \\
\hline $\begin{array}{l}\text { Counselling or deferral not } \\
\text { documented }\end{array}$ & $348(83.3 ; 79.3$ to 86.7$)$ \\
\hline $\begin{array}{l}\text { Counselling deferred to the } \\
\text { ward }\end{array}$ & $n=42$ \\
\hline $\begin{array}{l}\text { Counselling documented in } \\
\text { inpatient record }\end{array}$ & $15(35.7 ; 21.6$ to 52.0$)$ \\
\hline $\begin{array}{l}\text { Counselling not documented } \\
\text { in inpatient record }\end{array}$ & $27(64.3 ; 48.0$ to 78.4$)$ \\
\hline $\begin{array}{l}\text { HIV testing performed in the } \\
\text { ward }\end{array}$ & $n=1214$ \\
\hline $\begin{array}{l}\text { Pretest and post-test } \\
\text { counselling documented }\end{array}$ & $176(14.5 ; 12.6$ to 16.6$)$ \\
\hline $\begin{array}{l}\text { Only pretest counselling } \\
\text { documented }\end{array}$ & $34(2.8 ; 1.9$ to 3.9$)$ \\
\hline Counselling not documented & $1004(82.7 ; 80.4$ to 84.8$)$ \\
\hline
\end{tabular}

Table 3 HIV test results and counselling practices*

\begin{tabular}{ll}
\hline $\begin{array}{l}\text { All patients tested for HIV in ED } \\
\text { or ward }\end{array}$ & $\mathrm{n}=1632$ \\
$\quad$ Results positive & $239(14.6 ; 13.0$ to 16.5$)$ \\
Results negative & $974(59.7 ; 57.3$ to 62.1$)$ \\
No results documented & $419(25.7 ; 23.6$ to 27.9$)$ \\
HIV test positive & $\mathrm{n}=239$ \\
Counselling documented & $79(33.1 ; 27.1$ to 39.4$)$ \\
Counselling not documented & $160(66.9 ; 60.6$ to 72.9$)$ \\
HIV test result negative & $\mathrm{n}=974$ \\
Counselling documented & $11(1.1 ; 0.6$ to 2.0$)$ \\
Counselling not documented & $963(98.9 ; 98.0$ to 99.4$)$ \\
\hline
\end{tabular}

*Values are counts (\%; 95\% Cls).

ED, emergency department.

\section{Interobserver agreement}

A second physician, blinded to the findings of the first, independently abstracted a random sample of 126/1213 (10.4\%) charts containing HIV test results. The observed agreement for the documentation of pretest and post-test counselling was $97.6 \%$, corresponding to a Cohen's $\kappa$ of 0.90 (95\% CI 0.73 to 1.0$)$.

\section{DISCUSSION}

Sub-Saharan Africa has the greatest burden of children with HIV in the world. ${ }^{1} 21516$ Over the past decade, increased availability of HAART has substantially improved the quality of life and survival of many children born or infected with HIV/AIDS. ${ }^{17-19}$ In 2012, the National Aids Control Programme in Tanzania estimated the number of children below the age of 15 years living with HIV at $160000 .^{20}{ }^{21}$ Sadly, only 58245 of these children were enrolled in CTCs across the country and HIV/AIDS remains among the top 10 causes of death in children aged $<5$ years in Tanzania. ${ }^{22} 23$ The enrolment of these children into the CTC starts with HIV counselling and testing. However, with the challenges of poor health-seeking behaviour, HIV stigma and lack of provider initiated counselling and testing, many of these children may not get adequate screening and timely referral for disease-specific care. The ED is well positioned to play a role in filling this gap. While ED-based

Table 4 Documentation of patient referral for follow-up HIV care at the time of discharge ${ }^{*}$

\begin{tabular}{lc}
\hline All patients testing HIV positive & $\mathrm{n}=239$ \\
$\quad$ Survived to discharge & $199(83.3 ; 77.9$ to 87.8$)$ \\
$\quad$ Died in the hospital & $40(16.7 ; 12.2$ to 22.1$)$ \\
$\begin{array}{l}\text { HIV positive patients who } \\
\text { survived to discharge }\end{array}$ & $\mathrm{n}=199$ \\
$\quad \begin{array}{l}\text { Referral to HIV clinic } \\
\text { documented }\end{array}$ & $76(38.2 ; 31.4$ to 45.3$)$ \\
$\begin{array}{l}\text { Referral to HIV clinic not } \\
\text { documented }\end{array}$ & $123(61.8 ; 54.7$ to 68.6$)$ \\
\hline *Values are counts $(\% ; 95 \% \mathrm{Cls})$. &
\end{tabular}


testing is understandably targeted towards guiding immediate care priorities, appropriate counselling and CTC referral are imperative to realise the full benefit of HIV testing in any setting.

We were able to retrieve the charts of $96 \%$ of the children who presented to the MNH ED during the study period. We believe this is an impressive capture rate, especially given the previously documented challenges with health records utilisation and management in sub-Saharan countries. ${ }^{24-26}$ Furthermore, interobserver agreement among data abstractors was high, with the calculated Cohen's $\mathrm{\kappa}$ value representing 'almost perfect' agreement according to the classification of Landis and Koch. ${ }^{14}$

Nearly $30 \%$ of children were tested for HIV either in the ED or in the inpatient setting. This finding is similar to provider-initiated counselling and testing (PITC) rates previously documented in other hospitals across sub-Saharan Africa. ${ }^{27-29}$ Unfortunately, this is still a very low rate of PITC for an HIV endemic area, especially given the recommendations of many national and international guidelines, which advocate for increased PITC in HIV endemic areas in an effort to improve early recognition, optimise treatment and reduce new transmissions. ${ }^{10}{ }^{30}$ Moreover, we found that results were missing for more than one-quarter of children for whom a physician ordered HIV testing. It is unclear whether this was because the test was never performed or because the result was not properly documented. Either way, this is a significant concern, especially at a tertiary referral hospital in a main commercial hub of the country. This may be an indication of similar challenges in smaller healthcare facilities across the country, since these facilities will normally have more limitations in human resources and infrastructure.

The documented rates of counselling for children undergoing HIV testing in the ED were abysmally low. More than $80 \%$ of cases had no documentation of pretest and post-test counselling, or deferral of counselling to the inpatient service. When the emergency physician did document deferral of counselling, subsequent counselling was documented in the inpatient record in just over one-third of cases. While low, this was more than double the rate of counselling documented when HIV testing was initiated by the inpatient service. Overall, children who tested positive for HIV had a higher probability of receiving pretest and post-test counselling compared with those who tested negative, but the rates were unacceptably low for both groups. There are several possible reasons for these findings relating to our unique setting and study population. First, due to patient crowding in the MNH ED and wards, it is possible that the low rates of counselling were related to the lack of private space available for these sensitive conversations. Similarly, patient acuity and competing patient care demands in a busy public ED may have contributed to the low documentation rates. Finally, there may be unique patient and provider level challenges associated with counselling of this population due to the varying ages of the patients (young children vs adolescents), and the need to identify and counsel the responsible parent or guardian.

Our most striking finding was the low rate of referral for follow-up care. Of all patients with a positive HIV test result documented in their chart, referral to CTC follow-up was documented in $<40 \%$. While it is possible that counselling and follow-up referral were provided in some of these cases and simply not documented in the medical record, it is equally likely that a significant proportion of patients testing HIV positive were discharged without knowledge of their test results. This represents a lost opportunity for early intervention to mitigate the morbidity and mortality of the affected children, and a barrier to ongoing efforts aimed at preventing disease transmission. $^{2} 20$ 31-33 Thus, our findings suggest the need for further investigation of system factors, sociocultural considerations, and provider barriers to optimising ED and inpatient HIV services to inform system-based improvements to optimise the care of this vulnerable population.

\section{Limitations}

The limitations of this study include the retrospective design and the relative paucity of clinical data available from the medical record. We could only report whether or not HIV counselling and referral were documented in the patient charts. This methodology may underestimate the true counselling and referral rates, if these services were provided but not documented. Also, the analysis of counselling patterns by HIV test result (positive or negative) was limited by the fact that test result data were missing for 419/1632 (25.7\%) patients. Additionally, our data must be interpreted in the context of the study setting. As the MNH ED is one of only a few such academic EDs in sub-Saharan Africa, and the only such department in Tanzania, our data may not be generalisable to other settings. Finally, the majority of patients seen at the MNH ED are referred from other healthcare facilities and some may have had HIV testing prior to transfer. If the physicians caring for the patient at $\mathrm{MNH}$ were aware of such testing, that may explain the low overall testing rate. Despite these limitations, we believe that our data highlight an important opportunity to improve HIV testing, counselling and referral practices in a high-prevalence setting.

\section{CONCLUSIONS}

Among patients tested for HIV in the ED, emergency physicians documented the provision, or deferral, of counselling in less than a quarter of cases. When deferred to the inpatient setting, subsequent counselling was documented in just over one-third of cases. Counselling was much more likely to be documented when the test result was positive. Of those patients testing positive, referral to CTC follow-up after discharge was documented in less than half. We recommend 
future work focusing on optimising ED and inpatient HIV testing, counselling and referral practices.

\section{Author affiliations}

${ }^{1}$ Emergency Medicine Department, Muhimbili University of Health and Allied Sciences, Dar es Salaam, Tanzania

${ }^{2}$ Emergency Medicine Department, Muhimbili National Hospital, Dar es Salaam, Tanzania

${ }^{3}$ Department of Emergency Medicine and Global Health Sciences, University of California, San Francisco, California, USA

${ }^{4}$ Department of Emergency Medicine, Carolinas Medical Center, Charlotte, North Carolina, USA

Acknowledgements The authors thank Dr Brittany L Murray, Professor M Moshi and Dr Hedwiga Swai, for their support throughout the study period.

Contributors HRS contributed to the conception and design of the study, acquired, analysed and interpreted the data, and drafted and revised the manuscript. JAM contributed to the design of the study, data acquisition and entry, and also revised the manuscript. FHR contributed to the design of the study and critically revised the manuscript. VM contributed to the conception and assisted in the initial design of the study, and critically revised the manuscript. TAR contributed to the conception, assisted in the initial design of the study and data interpretation, and critically revised the manuscript. MSR contributed to the conception and assisted in the initial design of the study, analysed and interpreted the data, and critically revised the manuscript. All the authors read and approved the final manuscript.

Funding This research received no specific grant from any funding agency in the public, commercial or not-for-profit sectors.

Competing interests None declared.

Ethics approval The Senate Research and Publication Committee of the Muhimbili University of Health and Allied Sciences reviewed the study protocol and granted ethical clearance, including waiver of informed consent.

Provenance and peer review Not commissioned; externally peer reviewed.

Data sharing statement No additional data are available.

Open Access This is an Open Access article distributed in accordance with the Creative Commons Attribution Non Commercial (CC BY-NC 4.0) license, which permits others to distribute, remix, adapt, build upon this work noncommercially, and license their derivative works on different terms, provided the original work is properly cited and the use is non-commercial. See: http:// creativecommons.org/licenses/by-nc/4.0/

\section{REFERENCES}

1. Joint United Nations Report on HIV/AIDS 2013. UNAIDS. Core slides: global summary of the AIDS epidemic. 2013.

2. Joint United Nations Programme on HIV/AIDS. Global report: UNAIDS report on the global AIDS epidemic. Geneva: Joint United Nations Programme on HIV/AIDS, 2013.

3. Nkwo P. Prevention of mother to child transmission of human immunodeficiency virus: the nigerian perspective. Ann Med Health Sci Res 2012;2:56-65.

4. Newell ML, Coovadia H, Cortina-Borja M, et al. Mortality of infected and uninfected infants born to HIV-infected mothers in Africa: a pooled analysis. Lancet 2004;364:1236-43.

5. Coovadia HM, Rollins NC, Bland RM, et al. Mother-to-child transmission of HIV-1 infection during exclusive breastfeeding in the first 6 months of life: an intervention cohort study. Lancet 2007;369:1107-16.

6. Coutsoudis A, Pillay K, Spooner E, et al. Influence of infant-feeding patterns on early mother-to-child transmission of HIV-1 in Durban, South Africa: a prospective cohort study. South African Vitamin A Study Group. Lancet 1999;354:471-6.

7. Gibb DM, Duong T, Tookey PA, et al. Decline in mortality, AIDS, and hospital admissions in perinatally HIV-1 infected children in the United Kingdom and Ireland. BMJ 2003;327:1019.

8. Judd A, Doerholt K, Tookey PA, et al. Morbidity, mortality, and response to treatment by children in the United Kingdom and Ireland with perinatally acquired HIV infection during 1996-2006: planning for teenage and adult care. Clin Infect Dis 2007;45:918-24.

9. Bobat R, Moodley D, Coutsoudis A, et al. Breastfeeding by HIV-1-infected women and outcome in their infants: a cohort study from Durban, South Africa. AIDS 1997:11:1627-33.

10. The United Republic of Tanzania Ministry of Health and Social Welfare National AIDS Control Programme (NACP). National Guidelines for the Management of HIV and AIDS. Tanzania; 2012.

11. Reynolds T, Sawe HR, Lobue N, et al. Most frequent adult and pediatric diagnoses among 60,000 patients seen in a new urban emergency department in Dar es Salaam, Tanzania. Ann Emerg Med 2012;60:S39.

12. About Us-Muhimbili National Hospital (cited 9 December 2012). http://www.mnh.or.tz/index.php/about-us

13. Gilbert EH, Lowenstein SR, Koziol-McLain J, et al. Chart reviews in emergency medicine research: where are the methods? Ann Emerg Med 1996;27:305-8.

14. Landis JR, Koch GG. The measurement of observer agreement for categorical data. Biometrics 1977;33:159-74.

15. Ubesie A. Pediatric HIV/AIDS in sub-Saharan Africa: emerging issues and way forward. Afr Health Sci 2012;12:297-304.

16. Killian MS, Levy JA. HIV/AIDS: 30 years of progress and future challenges. Eur J Immunol 2011:41:3401-11.

17. Magafu MGMD, Moji K, Igumbor EU, et al. Usefulness of highly active antiretroviral therapy on health-related quality of life of adult recipients in Tanzania. AIDS Patient Care STDS 2009;23: 563-70.

18. Verweel G, van Rossum AMC, Hartwig NG, et al. Treatment with highly active antiretroviral therapy in human immunodeficiency virus type 1-infected children is associated with a sustained effect on growth. Pediatrics 2002;109:E25.

19. Guillén S, Ramos JT, Resino R, et al. Impact on weight and height with the use of HAART in HIV-infected children. Pediatr Infect Dis $J$ 2007:26:334-8.

20. The United Republic of Tanzania Ministry of Health and Social Welfare (Tanzania Mainland). Tanzania elimination of mother to child transmission of HIV plan, 2012-2015. http://www.emtct-iatt.org/wpcontent/uploads/2012/11/Costed-eMTCT-Plan-Final-Nov-20121.pdf (accessed 19 Mar 2014).

21. UNAIDS. The Global HIV/AIDS Epidemic. 2012 (cited 19 March 2014). http://kff.org/global-health-policy/fact-sheet/ the-global-hivaids-epidemic/

22. Nicks BA, Sawe HR, Juma AM, et al. The state of emergency medicine in the United Republic of Tanzania. Afr J Emerg Med 2012:2:97-102.

23. WHO 2008. The global burden of disease

24. Ndabarora E, Chipps JA, Uys L. Systematic review of health data quality management and best practices at community and district levels in LMIC. Info Dev 2014;30:103-120.

25. Athale UH, Chintu C. Clinical analysis of mortality in hospitalized Zambian children with sickle cell anaemia. East Afr Med J 1994;71:388-91.

26. Harries AD, Zachariah R, Lawn SD, et al. Strategies to improve patient retention on antiretroviral therapy in sub-Saharan Africa. Trop Med Int Health 2010;15(Suppl 1):70-5.

27. Coil CJ, Haukoos JS, Witt MD, et al. Evaluation of an emergency department referral system for outpatient HIV testing. J Acquir Immune Defic Syndr 2004;35:52-5.

28. Ramirez-Avila L, Noubary F, Pansegrouw D, et al. The Acceptability and feasibility of routine pediatric HIV testing in an outpatient clinic in Durban, South Africa. Pediatr Infect Dis $J$ 2013;32:1348-53

29. McCollum ED, Preidis GA, Golitko CL, et al. Routine inpatient human immunodeficiency virus testing system increases access to pediatric human immunodeficiency virus care in sub-Saharan Africa. Pediatr Infect Dis J 2011;30:e75-81.

30. World Health Organization. Towards universal access: scaling up priority HIV/AIDS interventions in the health sector: progress report 2010. http://apps. who.int/iris/bitstream/10665/44443/1/ 9789241500395_eng.pdf

31. Resino S, Resino R, Maria Bellón J, et al. Clinical outcomes improve with highly active antiretroviral therapy in vertically HIV type-1-infected children. Clin Infect Dis 2006;43:243-52.

32. Montaner JSG, Wood E, Kerr T, et al. Expanded highly active antiretroviral therapy coverage among HIV-positive drug users to improve individual and public health outcomes. J Acquir Immune Defic Syndr 2010;55(Suppl 1):S5-9.

33. Piot $P$, Coll Seck AM. International response to the HIV/AIDS epidemic: planning for success. Bull World Health Organ 2001;79:1106-12 